\title{
Mondes visuels
}

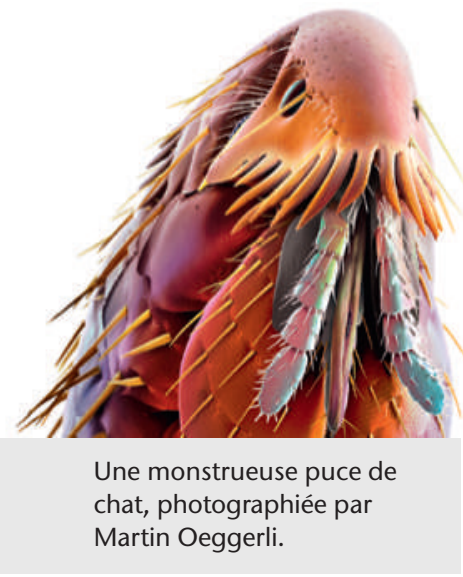

La visibilité des choses n'existe pas simplement. Elle est créée en dehors de nos sens et déterminée de manière expérimentale dans des laboratoires. Ce qui nous est donné à voir, ce sont des échantillons issus de la science, de l'art et de la technique. Bien qu'il s'agisse toujours de matériel organique préparé, la photomicrographie médicale est un outil de collecte d'informations indispensable depuis le milieu du $\mathrm{XIX}^{\mathrm{e}}$ siècle. Les instruments sont notre sixième sens. Des exoplanètes aux nano-objets, ils nous livrent des artefacts qui enrichissent notre collection d'images et modifient ainsi nos conceptions et nos actes.

Martin Oeggerli, né en 1974 et connu sous le pseudonyme de «Micronaut», compte parmi les virtuoses de la fusion de la technique et de l'art. C'est une star de la photo scientifique qui a remporté pas moins de dix-neuf prix internationaux prestigieux depuis 2006, ce qui équivaut à peu près à être multirécompensé aux Oscars dans le cinéma. National Geographic, GEO, Focus, Vogue, Nature, Cell, la BBC ou Bild der Wissenschaft s'arrachent ses œuvres.

\section{Le travail prend une à trois semaines, 20 à 30 images peuvent être préparées par an.}

Serein et modeste, il explique son travail à ses auditeurs lors de la rencontre de midi au Musée d'Histoire Naturelle à Saint-Gall, qui présente une sélection de ses photos mondialement célèbres dans le cadre de l'exposition spéciale «Faszination Mikrokosmos», une première en Suisse. Martin Oeggerli a étudié la biologie à Bâle. Alors qu'il examinait des poils de chauve-souris pour son mémoire, il s'est servi pour la première fois d'un microscope électronique à balayage (MEB) à la Haute Ecole de Life Sciences à Muttenz. Un processus d'une grande complexité, comme il le montre à l'écran en prenant pour exemple des clichés de pollen. Les particules de la taille d'un grain de poussière sont plongées dans une solution chimique pour figer les protéines et les lipides en une structure rigide, afin qu'ils ne se rétractent pas en se déshydratant. Les pollens sont revêtus d'un mélange d'or et de palladium dans une chambre à vide où, via des capteurs, un faisceau d'électrons relie chaque point de la surface désormais conductrice pour en donner une représentation d'une netteté saisissante. Les images sont en- suite colorisées grâce à l'informatique, un travail qui dure une à trois semaines et permet de réaliser 20 à 30 images par an. La grande profondeur de champ met en évidence de nombreux détails auxquels seule une coloration raffinée donne leur structure et leur profondeur dans l'espace. Des mondes bizarres d'une beauté fascinante. Des formes qui sidèrent même les spécialistes, en les confrontant à des organes totalement inconnus, qu'ils ne savent pas encore expliquer. Des créatures grossies jusqu'à 100000 fois, constituées de piquants, de mailles, de filets, de bourrelets et de sphères creuses. Des puces de chat et des acariens agrandis à la taille de monstres, qui heureusement ne partagent pas notre échelle humaine. On découvre des structures délicates, surprenantes de beauté et de complexité. De mystérieux mondes d'images, faits d'œufs d'insectes, de capsules de mousse, de spores, de bactéries et de surfaces de feuilles. De somptueux trésors des profondeurs issus de micromondes fantastiques: des réseaux de fibrine emprisonnant des érythrocytes, des couches rétiniennes, des yeux à facettes, des cellules cancéreuses invasives, de la peau de poisson, des larves de moustique et des tiques.

Des œuvres d'art qui attirent le regard et nous ouvrent les yeux, commandées pour des ouvrages didactiques, des contrats publicitaires, des projets photographiques et des entreprises de recherche, par exemple en pathologie à l'hôpital universitaire de Bâle. Si les travaux de Martin Oeggerli suscitent l'enthousiasme, c'est parce que son esthétique ouvre les portes de la science aux profanes. Albert Einstein a dit: «La plus belle chose que nous puissions éprouver, c'est le côté mystérieux de la vie. C'est le sentiment profond qui se trouve au berceau de l'art et de la science véritable.» Les microscopes électroniques et désormais le microscope à fluorescence très haute résolution récompensé par le prix Nobel enchantent le monde. Ils nous donnent accès à des dimensions époustouflantes. Une conception romantique: dans le mot se-cret, il y a «se». On en revient toujours à soi.

Erhard Taverna

\footnotetext{
Exposition: Faszination Mikrokosmos. Photographies scientifiques du Dr Martin Oeggerli, Musée d'Histoire Naturelle de Saint-Gall, jusqu'au 4.1.2015, www.naturmuseumsg.ch

- Site internet: www.micronaut.ch

- Livre: Oeggerli M. Micronavigating between science + art.
} 